\title{
Pandemics and the Adaption of Social Perception in Cohabitation with Viruses
}

\author{
Denis Celcima \\ $\mathrm{PhD}$, Lecturer of psychology at UBT-University \\ Lito Goga
}

Msc., Psychologist for children with a disability

\begin{abstract}
Pandemics have become a common word among us; all we have to do is to adapt our lifestyle in contradiction to our former. The famous expression "life is a rat race" has already gotten its replacements of rats into bats as it seems, but that is not all. It is still a race but in this case, is a race of patience, persistence in quarantine conditions due to physical and psychological viruses. There are a lot of questions that circles around us making visions for the future neither optimistic nor pessimistic ones. What is happening around the world and us? Are we ready to face such major changes that we do not even know whether they are to be called changes? However, one thing is for sure that our perceptions are undergoing into fundamental new ways of repairing their style or maybe ours or both. If the world is getting ready for the big leap in an unplanned future, so do our social perceptions. Men have gone to the moon, explored space, have given thoughts about the universe, have also ruined nature, polluted air but all these were included in the men's social perceptions. Now it seems that our fear of the unknown have risen along with the fear of unplanned risen of the new upcoming perceptions.
\end{abstract}

Keywords: Pandemics; cohabitation; social perceptions; quarantine; physical and psychological viruses.

\section{Introduction}

Since December 2019, we have had the first reports about a new epidemic and a new unknown virus called coronavirus or COVID-19 with the severe acute respiratory syndrome. The entire world has been suffering from this disease that rapidly transformed into a pandemic. Due to this unknown virus, almost all countries have introduced strategies of isolation such as quarantine. Although panic and fear of infection held people confined, the states kept recording and reporting mass infection and many deaths.

The famous and notorious lockdown was believed to get the trajectory of transmission lower and lower. Somehow it got lower, but a new catastrophic vision of the future was being drawn 
and people found themselves without work, isolated at home, most of them away from their families and above all with the emergency that fundamental change was unavoidable.

On the other side, people who contracted the virus were being treated as a death penalty to others and themselves. Their isolation was not only by the medical part but also by the social one as they were being kept in prison-like conditions. Even though these precautions were to maintain the safety of the public health, it kept under shock and stress the entire community. Nowadays, we listen to different protests against quarantine and isolation; this is a reference to the damage caused to the mental health.

The situation led to fundamental changes in perceptions not only socially, but also psychologically. Distance replaced the meaning of staying close and loving each-other not virtually. The world seems to be waiting on its knees; all humanity is expecting something unknown and differently perceived before. The life and sociological strata remain in a developed society, but with the economic crises rising and the poverty maximizing throughout the world. This pandemic situation has brought a lot of crisis including the economic one. The most influential countries in the world, as the United States, is suffering the unemployment rate and according to Monetary Fund, the proportion of people out of work has reached 10.4\%, which is a signal to the end of a new era and fundamental change in the entire world economy. In contradiction, even though the unemployment rate is accelerating, the world economy is expected to rise. So the wh-questions appeared in the call of adaptation, survival and consequently existence.

What is going to happen next?

How should we adapt?

Why the governments cannot give the right solution

Where are the world and humanity going?

When will end all of this?

The paradox is that none of these simple-looking questions seems to have a solution and the insecurity lays beyond our inner and outer world.

Everything claimed was on the hygiene, disinfectant liquid such as alcohol and the washing of the hands for about 20 seconds. Hasn't any hygiene been kept so far? Also, we cannot forget the mask. However, these precautions are right and should be the main formula of both sides; of science and humanity values. It is clear that pandemics is called a second great depression and the world is facing a great recession, so the more a depressive world, the more depressive people and society. All of this has caused a global pain and the future seems shocking socially, economically, psychologically and physically. The definition of health has changed because according to a recent survey, each of us might infect others without being sick with no symptoms of suffering by the virus. So health and healthy means sick without suffering. This 
causes fear of the unknown and fear of people, which is unusual to us as social and communal beings.

In this article, what we are trying to focus on, is the social perception and the adaptation needed in our cohabitation with this undefined virus.

\section{What is the social perception?}

As a definition social perception is a study of how people form their impressions of and make inferences about other people as sovereign personalities. Social perception refers to identifying and utilizing social cues to make judgements about social roles, rules, relationships, context, or the characteristics of other people. So, social perception helps us construct our personalities and is a major part of our socialization. We continue our normal lifestyle and take everything for granted. We take for granted our family, the fresh air, the environment, the food and we take for granted even our social status and life.

We will analyze the four main components of social perception but this case the viewpoint is by the disastrous aspect such as pandemics. These four components are:

- observation

- attribution

- integration

- confirmation

In contradict to our studied perception, COVID-19 has changed the ways that we are used to approaching the others, to share, to love, to touch, to get close, to dance with them and the feel of a part of a community has taken a deviation to social distance, the same as a sentence taken when people commit a crime. COVID -19 has destroyed the meaning of love, closure and the sacrifices for the others as a part of self-actualization and has caused to people panic and trauma if they are close to each other, touch, meet each other. As we may say, life has taken a different meaning-a meaning of living safe and sound within a considered distance

\section{Observation}

Observation is one of the most outstanding methods of learning and adaptation. There are different regions in our brain which are very active in response to social observation (Tylen et al.,12). To observe means to get your attention to the entire world, to nature and all the living things, so that you to get to know the life from its perspective and objectivity and turn the knowledge in the forming of your inner self as a subject in the service of the entire existence.

Each of the scientists that have undergone different researches about perception has found out the importance of observing, even though it is considered a simple one has played a major part in the connection with the ability to know. Through observation, we perform the first form of knowledge and begin socializing with others. Observation forms are our first experiences of distinguishing what is right, from what is wrong. In a certain way, it allows us to percept freedom to choose and accept duties as well. This way we start forming our 
personalities and also to decide to keep tight to our inner self or adapt to such a way of transforming it without changing our fundamental part.

Let analyze observation during pandemics. As we mentioned before, since December, we have begun to listen and watch different news about COVID-19. In the beginning, the situation was frightening and alarming, only depended on news and it wasn't possible to change our perceptions deeply and immediately. Our perception of China being so far and so common with the viruses hasn't affected our way of living, unlike now.

By the time that the virus began its eruption, that was the high time that fear and panic make themselves present among us and that is the moment when observation re-took its part in our conscious in another new and unpredicted way that didn't depend on us. The first step of the impact of observation were the long queues created for food and other necessary items because something terrible was going to happen and there were a lot of death reports. A lot of countries started to suffer from the virus and the situation worsened. The isolation was happening and people and states were forced to give up from the basic human rights such as free movement, the right of working, meeting friends, the right of practising of the religion and having a normal life. People began the perception of the insecurity and fear especially with the death numbers that kept rising and the World Health Organization wasn't able to give the proper explanation and proper precautions, so it wasn't capable to inform people and doing its duty. The question; what was going to happen -ruled the entire world and while we observing the silence, the missing of the information and the sense of the unknown, the time of enslaving freedom of speech and thinking had already begun. That was the quarantine startup. The states began to violate their citizens and no one was allowed to move outside or to go to work because they put restrictions and kept the people of the contacts as the only measure ordered by the WHO. The questions were shut and the perception was turned to the obedience. Everybody started to obey and stay locked inside when the lockdown happened. In the beginning, the lockdown was associated with the sense of being off work or as a type of holiday. This perception helped somehow ease to the obedience. The main form of observation has become the media and the internet. The focus of attention was the news and the reality couldn't be perceived any more in the common way, but only through TV and on the internet. It seemed that everyone was under hypnosis which was caused by the fear of this unknown and invisible "enemy". Everything was paralyzed and the image of a new type of war, was present. This perception of the war was strengthened with the military standing on the street, to keep people inside their shelters of security. Army, soldiers, weapon were used to make people stay closed so that they might be safe against the terrible enemy called COVID-19. The paradox standing among was the war and the peace at the same time. How should the situation be defined? The observation techniques led us to perceive violation by the society's organism which was meant to protect our life of present and future and we were between the thought of the necessity of violence and terror to keep the world and people safe from the COVID-19. How come the violence is used to make someone feels sure for its wellbeing?

On the other hand, there might appear a problem, because even the best and capable observers can have the wrong perception and might come to prejudices and wrong conclusions. Consequently, forming the wrong impression leads to the wrong persistence. The great dilemma here is that we do not feel secure if, what we percept is right or wrong because the 
challenge presented was the high flush of information and different theories about the virus, the truth and the solution.

"Misinformation is not new", said communications Fleming (Under-Secretary-General for Global Communications). "We've had misinformation as far back as you look in history. The difference here is that we have a global pandemic that is happening in the social media age."

\section{Attribution}

As the second element of social perception is the process of the forming of the impressions of other people to accept them as they are. The attribution here stands that generally, we attribute to others and the world by combining different impressions to make ourselves ready to socialize.

The wisdom deriving by the need to survive leads to the need for the same cohabitation with viruses and disease. This is not our first experience with a disastrous feature of life, but according to Dr Briand, when people are anxious and uncertain of several things they tend to compare with things they know already or things they have experienced in the past. We attribute to others for ourselves, the same our perception should focus on a kind of agreement with adaptation and living with viruses and bacteria the same as our ancestors did, that is why it cannot be performed without observation. During this period, along with the perception of viruses phases, there appears the habit or the necessity of ordering the world. As usual, we categorize people due to our perception of usefulness and at the same time, we put ourselves in the same position. During the COVID-19 time, the problem is that firstly we were put in the same time to the two positions and after getting used to it, we felt sometimes to be weak to such immediate adaptation. At least, at our pre-COVID-19 perception the different happenings and items are related similarly to each other so we were comfortable with this perception created and socialization achieved. All the subjects and objects that were taken for granted and were useful to us, suddenly become a sandcastle, not resistant to the waves. This normally causes panic and anxiety. The new classifications done during pandemics have helped to form our attitudes, but the change needs time firstly to form the right knowledge and to accept the change to ourselves and then to make the knowledge in the function of attitudes. During an observation, we learn to pay attention to some of our stimuli while we abandon some others. This way we form our attribution by our experience to mind or not different items. Social attribution allows us to see beyond what it is seen. Thus, even in a disastrous situation, we can form additional facts to know how to cope with the new extraordinary state of being and consciousness. According to the attribution theory, we are helped to know how to relate to people and object. The difficulty here stands that our perception of people and objects has gone under a drastic change because we firstly should percept an invisible and terrible enemy then have the perception on how to behave with people and objects. The quarantine and isolation period revealed the incapacity of the so-called post modernism to give a solution and the cure for the COVID-19. The individualism claimed through all this period changed all the paradigm of living for oneself. Just "me, myself and I", couldn't have the same result in the quarantine conditions. Life is seen as a harsh one, as a rat race appeared to suffer an abrupt halt and closure. All of a sudden necessity to be a fundamental part of the entire, to understand that individual happiness wasn't possible if there was no collective happiness.

A question rises this case: Did the virus get our social conscious awakened or we should reconstruct our way of thinking in the purpose of our survival and existence. "What is very important in this period now, because we don't have yet the vaccine, is to start building a space 
for a very open dialogue, a two-way dialogue with the population so we can hear their concerns and we can answer their concerns for as much as we can" Sylvie Briand

According to a research conducted by Brooking institution "In 2019, the Global Preparedness Monitoring Board published the report "A World At Risk," claiming "there is a very real threat of a rapidly moving, highly lethal pandemic of a respiratory pathogen killing 50 to 80 million people and wiping out nearly $5 \%$ of the world's economy.

By analyzing the situations, even though there is an insecurity that inspires the unknown and a state of anxiety, this still allows us to predict behaviour. As Hobs cited our natural state is "the fight of all against all" and the natural reaction of us according to Jung, is "escape or fight".

\section{The changing of a concept}

Mentioning again Carl Jung, "man was thinking before he realized he was thinking". The archetypes are simply the architecture of the collective unconscious; we can raise different questions.

What about social perceptions? Are they portrayed in the architecture of humanity? It is important to clarify that during this pandemic has changed even our concepts of being a hero.

Stay home, keep distance, wear a mask, be careful to your familiars, stay away to the beloved ones and some others more. Being a couch potato by only minding ourselves is perceived as something heroic and sacrificing. As we previously mentioned the big dilemma is to stay isolated as individuals when the rise of social consciousness is the most necessary thing to do. Even Neoliberals would find and prove hardship to such situation. It seems that the famous expression "To be or not to be" is being transformed to "from utopia to dystopia".

Due to these conditions, the misleading of information brings the deformation of our concepts and vice versa the deformation of the concept leads to the wrong information. A study which was directed by researchers from Harvard University suggested that under-25s (youngsters) in the United States are most likely to believe virus-related misinformation about the severity and the hardship of the disease and how it originated.

The world attitude of living is found to be such an illusion because all the so-called Democratic Institution are found being with some fascism characteristics where only force and violence are efficient. As we are being forcefully obligated to face an unwanted cohabitation with the virus and all the psychopathic tendencies of ruling the world, the new order and the same old alliances. This is noticed with the latest events and political conflicts happening. This way our attribution gets some confusion and requires a new way of adaptation to be part of the new social perception. In reality, this kind of obligatory adaptation is connected with the necessary part of perception process named integration.

\section{Integration}

How we classify people and things? We firstly get integrated with the way people feel, but at the same time, this happens according to our feelings. We identify them by their character and profession. We think of them as intelligent, creative, introvert, engineers, swimmers and our integration is tightly connected with the ways that how to get them to what we want to pursue our goals. This may sound egoist but each of us would tolerate it because we get all in the same place. Integration usually is helped by observation (Gelade and Treisman) and the difficulty with the pre and along virus, the situation is exactly the item of not knowing how to perceive 
the pandemics, social isolation and the need of saving your own and the entire world. What we see is far beyond the true meaning of the sight and we are often getting illusions by the reality and everything we are learnt to be real.

Firstly, we try to prepare ourselves to focus on the subject and the attribution. Normally this phase comes instinctively and is born with us the same as our character. The need for socialization passes our perception in the second stage to get focused on our inner selves, or our character and combine it and make complete perception. If we connect the integration with our perception of the virus and the pan problems that it causes, we will discover that the real nightmare that our social perception is having, is the lack of time that we possess to understand, to value, to get our attention focused and react. In such cases, we feel blocked because we aren't sure for how long we are being in such condition. After all, the insecurity circulates us in our real life. We are tired by the lockdown and the warns that it will come back as before. "One of the greatest dangers we face now is complacency. People in countries with stay-at-home orders are understandably frustrated with being confined to their homes for weeks on end", chief Tedros Adhanom Ghebreyesus reported. Such insecurity doesn't permit our integration in any field of life consequently, we cannot give the right confirmation of continuing the living in a new form of adaptation and perceptions about the presented life style.

\section{Confirmation}

According to the confirmation, the perceived performance of the virus curb, is unstable and unexplainable, our confirmation cannot bring the required satisfaction. This case we face a discomfort zone of our perceptions, we feel in disequilibrium because the entire science seems to have given up, or for the worst they are ordered to do so and nowadays the world order is put on politics hands rather than science. Consequently the link between expectations and performance is hard to be drawn and satisfaction is negated and the mental and perception crisis is that you have to get adapted to accept the perception of looser as successful, the same as the healthy sick patients or the so called asymptomatic. As for confirmation and expectations theory, "If a product outperforms expectations (positive disconfirmation) postpurchase (materially and perceptively) satisfaction will result. If a product falls short of expectations (negative disconfirmation) is likely to be dissatisfied (Oliver, 1980; Spreng et al. 1996).

The perception of the isolation and the pandemics reflect the insecurity with the expectation because we do not know to anticipate the understanding of the event and the anticipation of the behavior.

Normally There are predictive, indicating expected attributes at some point in the future (Spreng et al. 1996 and the evaluation that we make is fruitful according to the case taken.

Can we use our experience as we usually do? Expectations serve as a confirmation standard. If we cannot have the meaning of what we are expecting, how we might confirm the necessary decision to be taken. The root of the problem stands in the fact of the absence of the predictive expectations (that we cannot take) in the service of the perceived performance (we cannot act). COVID -19 is considered as a pain in the brain and the stigma and discrimination are confirmed to happen. Are we becoming socially unwanted beings? This seems to become a paradox because humans and humanity are related very close to the meaning of existence and the society. Our mindset is perceiving this virus as a killer even of mental health not only 
biologically, but also psychologically. Children feel strained and forced to become managers of themselves, by conducting their emotions and intellect to the ever changing performance and perceptions.

Are we able to confirm or getting confirmed to the insecurity which on the other part, the only confirmation that applies is the fear, the shock, panic and undeniable end of dying from depression

What is important to be cited to support a positive confirmation is the important statement of WHO organization to all the countries: "We call on Member States to develop and implement action plans to manage the infodemic by promoting the timely dissemination of accurate information, based on science and evidence, to all communities, and in particular high-risk groups; and preventing the spread, and combating, mis- and disinformation while respecting freedom of expression. It is urgent to become conscious and have the right perception of the situation if we want to live a peacefully life with nature and ourselves (WHO statement).

We need to turn our rights back because they symbolize the true nature and face of humans that we are.

\section{Conclusion}

The conclusion from the first blow of COVID-19 is that fear was planted in the world with the help of Political Powers in the states by "denying the Rights of the citizens, gained since previous millennia" as:

The right to free movement of citizens and goods, inside and outside countries.

The Right to Work, which provides all humanity the human well-being.

The Right to Traditional Education, and Selected Practice of Students in the World (inside the classroom).

The right to apply the rites of all Religious Beliefs.

The right to cure all diseases and the proper functioning of the hospitals. Now "it seems that only COVID 19 is being treated".

It is necessary humanity to be reminded that a few years ago a S1N1 Virus or FLU was introduced in the World and which did not succeed in instilling enough fear in humanity, to damage the Natural Immune System with biological antibodies. Now, with the appearance of the Corona virus the fear applied, succeeded to destroy the half of our immune system of the body and mind. If we have a lockdown map we can see that only the Scandinavian countries did not implement the Methods of Social Distance, and other Measures, "commissioned by the World Health Organization", on the grounds that we would develop Natural Biological Immunity. Standing by this logic, the Scandinavians showed solidarity with many Political Parties, Associations, Independent Organizations in the World. Distinguishing the different 
methods of facing the virus, people organized Mass Protests against the so-called supporters of the measures against COVID-19.

Humanity in these measures "against COVID-19 discovers" that some dark circles through these methods, impose on humanity:

$$
\begin{array}{ll}
- & \text { fear } \\
- & \text { isolation } \\
- & \text { unemployment } \\
- & \text { weakening of the education } \\
- & \text { poverty }
\end{array}
$$

Surprisingly, with such economic collapse we can perceive the enormous enrichment of Giant Pharmacy Companies around the World causing exactly the deepening of the division of humanity into the extremely rich and the extremely Poor. The situation created by AntiCOVID-19 Measures, highlights the claim that the Wealth Resources of Planet Earth are sufficient for just 1 billion inhabitants, which means that 6 billion inhabitants are redundant on this Planet. There is a mixture of the fear, insecurity, the protection dilemma between children and parents. During the quarantine period the fear and stress was after one month because this one was taken as days off work and a type of unplanned holiday. Almost all the people enjoyed their time with the close family even though becoming nervous easily was noticeable. After the first month the positivity of people who were in quarantine got lost and the fear from virus was associated with the fear of losing the job and the insecurity for the future. What was expected was unknown and frightening and consequently the perceived performance was not with the appropriate rhythm, because nobody knew what route to take. Everything was hanged nowhere but still hanged.

Even post quarantine period has been difficult to adapt. We still have a bat and rat race but this time by putting our masks on. Here we reach at the disconfirmation and we feel to be too far from the satisfaction. This prolonged situation of the cohabitation with the virus stands on insecurity because the WHO still remains alarming about the virus killing people and all of this, except the disconfirmation there is a huge delusion for the poverty, unemployment and the failure of this extremely modernized society.

\section{Is this development all for real?}

One thing is for sure though. The nature has donated us our immune system, has donated our humanity and the security for life is the love of nature and its law, the love and protection of what is human because is the true meaning of ourselves.

If this virus has caused the reflection about what is really important to be saved, to be honored and to be loved, may people and the states, learn to be communicative with nature, the universe laws and the humanity inside them, so that this painful event serves as a lesson for us and the future generation, to maintain the physical and mental health. It is considered of a great importance the freedom to think, to speak and of course the freedom of living. Using and keeping anxiety, does not help at all in each of the cases that people have experienced. Motivation is required to have a clear mind and a healthy body. In one of his books, Carl Jung cited: The absence of the possibility to give this machines a earthly base, made it possible to 
give them an extra-terrestial meaning. In this option all the voices were gathered into the Psychology of the huge panic ("A modern myth", Carl Jung p.9). So it is quite known why we are in such shock and panic, because we are eager to act in panic.

What is worth keeping valuing and loving still needs to be analyzed.

It remains to be seen whether mankind will organize self-defense, or "allow the painful change of life perceptions" expected to be happening by the predicted practice of the Second Strike of COVID-19.

This Biological-Viral War between the darkest circles of viruses spreading in the World, and of the six billion inhabitants of the Planet stand to yield results of pro-peaceful living, freedom, work, human harmony, education and love things that are divine gifts to mankind.

Who looks outside, dreams; who looks inside, awakes.

Everything that irritates us about others can lead us to an understanding of ourselves.

There is no coming to consciousness without pain. Carl Jung

\section{References}

[1] The evolution of early symbolic behavior in Homo sapiens Tylen et al.,12)

[2] Research conducted by Brooking institution "In 2019, the Global Preparedness Monitoring Board published the report "A World At Risk,"

[3] "Modern man in search of the soul"1933 Carl Jung

[4] "Psychology of the Unconscious"1912 Carl Jung

[5] "Archetypes and the Collective Unconscious" Second Edition Carl Jung

[6] “The Psychology of Interpersonal Relations" Fritz Heider

[7] The life of a psychologist: An autobiography. Lawrence, KS: University of Kansas Press. Heider, F. (1983).

[8] Fritz Heider: The Notebooks: Volumes 1-6. Springer. ISBN 978-0387912998 Heider, F., and M. Benesh-Weiner. (1987-1990).

[9] "Unskilled and unaware of it: How difficulties in recognizing one's own incompetence lead to inflated self-assessments". Journal of Personality and Social Psychology. 77 (6): 1121-1134. Kruger, J. M.; Dunning, D. (1999).

[10] An empirical examination of a model of perceived service quality and satisfaction Journal of Retailing

[11] Volume 72, Issue 2, Summer 1996, Pages 201-214lRichard A.Spreng ,Robert D.Mackoy

[12] Managing the COVID-19 infodemic: Promoting healthy behaviours and mitigating the harm from misinformation and disinformation WHO research; 23 September 2020

[13] Coronavirus: A visual guide to the economic impact By Lora Jones, Daniele Palumbo 


\section{\& David Brown}

[14] Coronavirus: 'World faces worst recession since Great Depression' By Szu Ping ChanBusiness reporter, BBC New COVID-19: 'Legitimate concerns' must be heard, and fears addressed over misinformation ; Global perspective Human stories.

[15] "A feature-integration theory of attention." Cognitive Psychology, Vol. 12, No. 1, pp. 97-136. Anne Treisman and Garry Gelade (1980).

[16] Still 'a long way to go' in coronavirus battle, WHO chief warns; Human stories 